\title{
The analysis of the channel deformations in the lower pool of the Votkinsk reservoir
}

\author{
Svetlana Dvinskikh ${ }^{1 *}$, Dmitriy Klimenko ${ }^{1}$, Olga Larchenko ${ }^{1}$, and Konstantin Minkin ${ }^{2}$ \\ ${ }^{1}$ Perm State University, Bukirev St. 15, 614990 Perm, Russia \\ 2"Nedra", Research, Design and Production Environmental Protection Enterprise, Lev Shatrov St. \\ 13a, 614064 Perm, Russia
}

\begin{abstract}
The sand and gravel mix is mined at the Votkinsk reservoir. This leads to horizontal and vertical channel deformations. To study them, we examined the Golyanovsk section of the sand and gravel mix (SAGM) field in the lower pool of the reservoir. We used the channel surveys made in 2012-2016, 2018 and 2019 as the source of cartographic materials. The lower pool section of the Votkinsk hydroelectric complex, within which the Golyanovsk SAGM field is located, is characterized by a fully regulated effluent and an unsteady hydrological regime. Therefore, the hydrological regime of the considered area is particularly complex and depends on the water consumption in the alignment of the Votkinsk hydroelectric station and the level of the Nizhnekamsk reservoir. The average long-term water discharge for the navigation period is $2200 \mathrm{~m}^{3} / \mathrm{s}$, the average long-term minimum monthly discharge rate is $1800 \mathrm{~m}^{3} / \mathrm{s}$. The field survey of the area was carried out during the low water period in accordance. This period was characterized by minimum levels at around 64.79-65.24 m BS. The water discharge varied between $1720-1780 \mathrm{~m}^{3} / \mathrm{s}$. With this flow, the Kama River is characterized by fairly low flow speed: no more than $1.29 \mathrm{~m} / \mathrm{s}$ on the rod and $0.2-0.5 \mathrm{~m} / \mathrm{s}$ on the riverbank shallows. The channel deposits are represented by pebble-gravel soils of various sizes. Throughout 2001-2019 an increase in the particle size has occurred. This is due to the change of the channel-forming process from accumulation to erosion. Horizontal deformations are represented by the reformation of the riverbanks, vertical - by accumulation and erosion of bottom. Drawdown levels are the result of natural deformations of the channel. According to the monitoring data, the duration of the "drawdown - growth" cycle is 2-3 years. The duration of the "drawdown - growth" cycle is $2-3$ years.
\end{abstract}

* Corresponding author: dvins@mail.ru 


\section{Introduction}

The Kama channel is characterized by a relatively flat bottom relief, the difference between the marks of adjacent reaches and rifts does not exceed $3 \mathrm{~m}$. In the reaches, the depth along the axis of the ships course at the normal headwater level (NHL) is $5-6 \mathrm{~m}$. Throughout the whole section, the area has a left-bank floodplain. The morphology of the channel is determined by the rift located here (the Golyanovsk rift). The monitored area includes the middle and the lower roll crests, a part of the upper and lower inner reach hollows, as well as three underdeveloped sidelines (Fig. 1). Below Golyanovsk island there is an extended reach area.

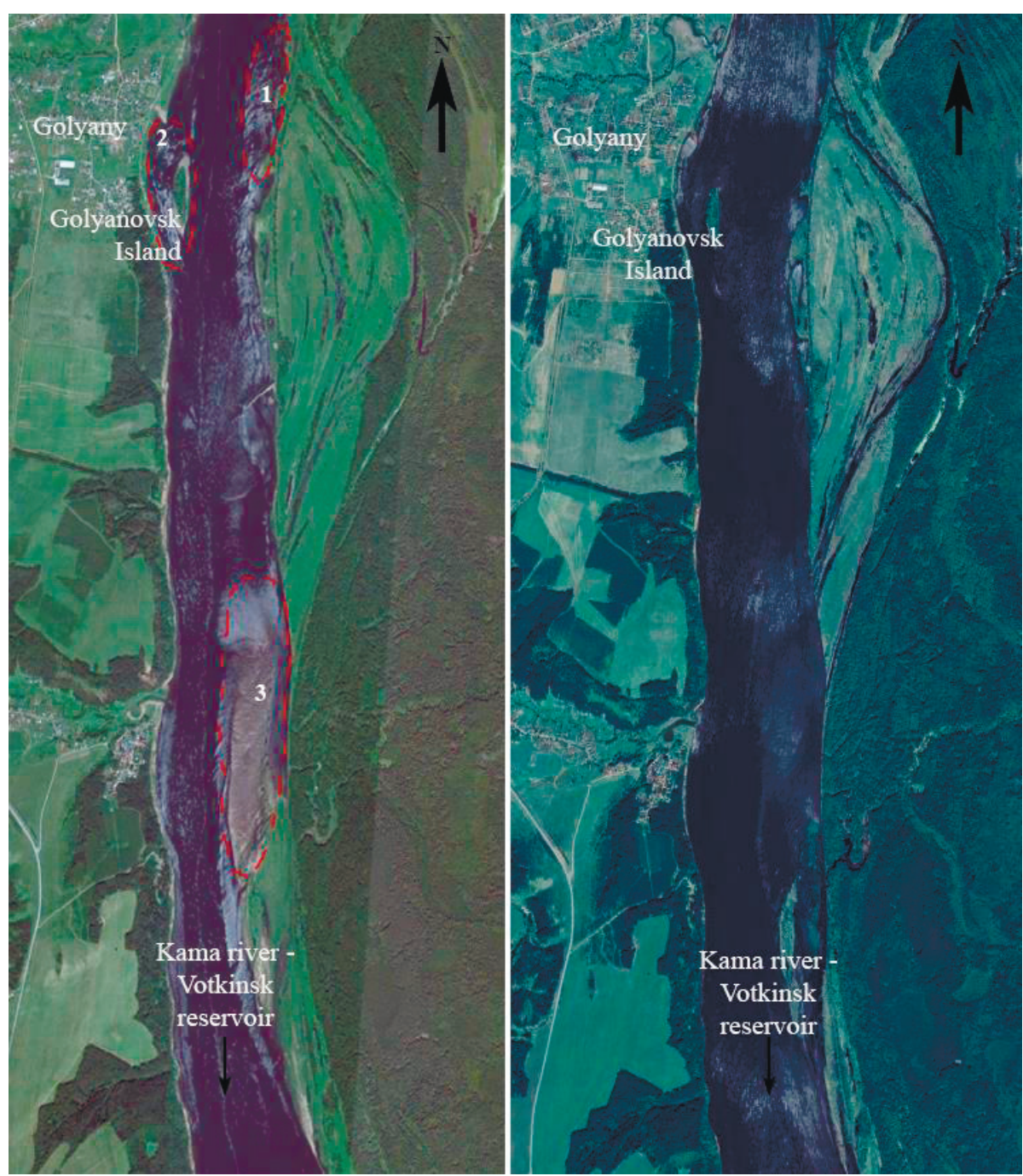

Fig. The location of the sidelines 1, 2 and 3 on the Golyanovsk rift section: 2016 (on the left) and 2019 (on the right).

The main source of the channel-forming material is the destruction of the floodplain and erosion of the riverine sandbars. The channel-forming material is redeposited to the channel and the banks. The single-arm channel accumulation regions are of a separate character, 
they are located mainly along the left floodplain bank at a considerable distance from each other in the form of elongated riverine sandbars. Channel deposits consist of sands of different granularity, gravel and pebbles [3].

From 2007 to 2012 on the Golyanovsk field, the bottom material was gradually enlarged, the weighted average diameter of channel deposits increased from $3.2 \mathrm{~mm}$ in 2007 to $15.4 \mathrm{~mm}$ in 2012 and $16.0 \mathrm{~mm}$ in 2019. The channel-forming sediments are represented by pebbles, gravel and sand of various grain sizes. The long-term increase in the size of bottom sediments is a consequence of the directed deep erosion - the leading modern process that determines the nature of the channel reformation in this area.

\section{Horizontal deformations}

The investigated area of the Kama river is characterized by moderate development of horizontal channel deformations, which is due to the flat nature of the flow, a slight tortuous channel, the presence of the root bank, and a relatively large size of the channel alluvium. The most common type of deformation is the erosion of the floodplain shores. A characteristic consequence of the predominant erosion is a directed decrease in the area of most of the islands represented on the site [4]. Horizontal deformations in the area of the Golyanovsk field mean the reformation of the riverbanks. The side walls on the left and right banks are partially eroded, the area of the Golyanovsk Island has significantly decreased. From 1995 to 2006 its area has decreased by $43 \%$.

\section{Vertical deformations}

Vertical deformations were estimated by combining longitudinal and transverse plans, as well as channel surveys for 2001-2019. The comparison of longitudinal profiles constructed along the ship passage for 2001 and 2009 shows that the bottom line has decreased: in the upper and lower reaches of the hollows of the Golyanovsk rift, the decrease is 1.2-1.5 m; on the crest of the rift it is $0.5 \mathrm{~m}$. The greatest decrease (by $1.8 \mathrm{~m}$ ) is noted at $1887.2 \mathrm{~km}$, where the lower crest of the rift has eroded. Obviously, during 2001-2009 a general lowering of the bottom marks is observed, reflecting the long-term tendency of the development of the Kama river channel - a directional erosion of the channel.

The analysis of the 2012 and 2016 surveys reflects the opposite picture - an accumulation is observed throughout the entire shipway. Combining bathymetric surveys for 2016 and 2018 one can see that the position of the longitudinal profile along the shipway line has returned to the state of 2001: the bottom marks have decreased almost throughout the entire area.

The reaches are introduced into the low water by sandy material, and are washed out during the high water $[2,5,6]$. Due to the lack of channel-forming sediments, specific for the downstream of the Votkinsk hydroelectric station, more sediment is carried out from the reaches than carried in, which results in their deepening. A relatively small decrease of the bottom on the crest of the Golyanovsk rift is associated with its geological structure - the rift shaft is composed mainly by the erosion-resistant gravel and pebble material. Throughout 2012-2016 the unidirectional process is observed along the entire length of the examined area - the sediment accumulation varies from 0.7 to $1.5 \mathrm{~m}$. During 2016-2018 the areas of erosion and accumulation alternate, the tendency to unidirectional erosion or alluvium is not observed. The deformation values are small $(\approx 0.5 \mathrm{~m})$. As a result, the bottom state is constantly changing.

We used the digital bathymetric plans of the 1886-1891.2 km section of the Kama river for 2016 and 2018 as the source materials for the analysis of the vertical deformations of 
the channel. Based on them, the digital elevation models - depth matrices - were created. By using the latter we performed the morphometric calculations. We subtracted the primary and secondary depth matrices and obtained a deformation matrix for the period of 20162018.

It turned out that the area occupied by erosion $\left(2370\right.$ thousand $\left.\mathrm{m}^{2}\right)$ is almost 1.4 times larger than the accumulation area $\left(1740\right.$ thousand $\left.\mathrm{m}^{2}\right)$. At the same time, the accumulation volume, as well as the layer thickness, exceeds the same erosion indicators (Table.).The erosion occurs throughout the entire area of the channel in separate small areas. Several areas with maximum erosion are quite clearly traced. The first of them is located along the right bank at the head and in the tail of the Golyanovsk island, the values reach 2.5 and 1.5 $\mathrm{m}$, respectively.

Table. The parameters of channel deformations in the examined area for 2016-2018.

\begin{tabular}{|c|c|c|c|c|c|}
\hline $\begin{array}{c}\text { Deformation } \\
\text { type }\end{array}$ & $\begin{array}{c}\text { Area, } \\
\mathbf{m}^{\mathbf{2}}\end{array}$ & $\begin{array}{c}\text { Share of the } \\
\text { channel area, } \\
\mathbf{\%}\end{array}$ & $\begin{array}{c}\text { Deformation } \\
\text { volume, } \mathbf{~ m}^{\mathbf{3}}\end{array}$ & $\begin{array}{c}\text { Share of the } \\
\text { volume of the } \\
\text { channel, \% }\end{array}$ & Layer, $\mathbf{m}$ \\
\hline Accumulation & 1742134 & 42,3 & 1159998 & 55,0 & 0,67 \\
\hline Erosion & 2373241 & 57,7 & 948117 & 45,0 & 0,40 \\
\hline
\end{tabular}

The second area of erosion lays in the central part of the channel at 1886.7-1888.9 km, with a maximum erosion value of $1.2 \mathrm{~m}$. It is the largest one in the area under consideration. The average erosion here reaches up to $0.9 \mathrm{~m}$. Around the selected erosion zone, the accumulation region with a value of only a few $\mathrm{cm}$ can be clearly traced. With an increase in the flow rate, the process direction here may change to the opposite.

\section{Conclusion}

The following conclusions are drawn:

1. The morphology of the channel in the field area is determined by the rifle located here (the Golyanovsk rifle), formed by three ridges and two internal hollows separating them.

2. The channel deposits are represented by pebble-gravel soils of various sizes. Sands cover about $35 \%$ of the total channel area. The weighted average diameter of the bottom material is $2.5 \mathrm{~mm}$. Throughout 2001-2019 an increase in the particle size has occurred. This is due to the change of the channel-forming process from accumulation to erosion.

3. Horizontal deformations are represented by the reformation of the riverbanks. The side walls on the left and right banks are partially eroded, the area of Golyanovsk Island has significantly decreased.

4. From 2016 to 2018 the volume of the channel has decreased by approximately 211 thousand $\mathrm{m}^{3}$ or $10 \%$ of its initial volume, which indicates the predominance of accumulation. At the same time, the area of the channel remained virtually unchanged. Therefore, the accumulation has a vertical orientation. However, vertical channel deformations did not retain the tendency of the previous period (2012-2016) - which would result in an increase in the bottom marks. On the contrary, their decrease is traced. The bottom marks approached the 2001 results in the lower part of the site and the 2009 marks in the upper part of the site.

5. Drawdown levels are the result of natural deformations of the channel. As a result of the displacement of the macroforms, the sections of the rolls smoothly shift downstream. 
Consequently, the duration of the level landing period will be proportional to the time of complete displacement of the macroforms, and the drawdown process itself is reversible, and over time it will inevitably turn into an increase in levels. According to the monitoring data, the duration of the "drawdown - growth" cycle is 2-3 years.

\section{References}

1. GKINP-02-033-82 Instructions for topographic surveys at the scales of 1:5000, 1:2000, $1: 1000,1: 500$.

2. GKINP (ONTA) 02-262-02 Instructions for developing a survey control network and performing a site and terrain survey using GLONASS and GPS global navigation satellite systems GLONASS / GPS.

3. GOST 12536-2014. Soils. Methods of laboratory determination of grain (particle size) and microaggregate composition. Moscow. Standartinform (2015)

4. The impact assessment of the hydromechanized development of the Golyanovsk and Makarovsk SAGM field on the hydrological and channel regime of the Kama on the Votkinsk hydroelectric station in Sarapul. The report of the Faculty of Geography, Moscow State University. Moscow (2007)

5. OST 25100-G2011. Soils. Classification. Mjscow. Standartinform (2013)

6. R.S. Chalov, Channel research (selected chapters from the course «Introductorytechnical surveys»): Textbook. Moscow. Moscow University Publishing House (1995) 